\title{
LAZER, A VIDA ALÉM DO TRABALHO PARA UMA EQUIPE DE FUTEBOL ENTRE TRABALHADORES DE HOSPITAL ${ }^{1}$
}

Rosângela Andrade Aukar de Camargo ${ }^{2}$ Sônia Maria Villela Bueno ${ }^{3}$

Camargo RAA, Bueno SMV. Lazer, a vida além do trabalho para uma equipe de futebol entre trabalhadores de hospital. Rev Latino-am Enfermagem 2003 julho-agosto; 11(4):490-8.

Visando a promoção da saúde mental do trabalhador, e minimizar o estresse e fadiga no cotidiano profissional, investigamos o significado do trabalho, do lazer e suas implicações, para 24 homens, trabalhadores de um hospital-escola paulista, que integram uma equipe de futebol, freqüentadores da associação recreativa desta unidade. Optamos pela Pesquisa Ação, numa abordagem humanista, qualitativa, analisando as falas por categorização, subsidiando a elaboração do projeto educativo. Coletamos dados através de entrevistas e observação participante e a fotografia como instrumento de apoio. Os pesquisados, na maioria casados, com filhos, recebendo, em média, $R \$ 650,00$, trabalham em locais próximos, favorecendo os contatos para os jogos. Para eles, o trabalho, garante a sobrevivência pessoal e familiar, e o lazer, diversão, descanso, integração e valorização da família e dos amigos. Evidenciam a importância do desafio no futebol, meio propulsor de promoção de saúde, resgate da auto-estima, alegria, liberdade, criatividade, espontaneidade, preparando-o melhor para a vida pessoal e profissional.

DESCRITORES: promoção da saúde; trabalho; atividades de lazer

\section{LEISURE, LIFE BESIDES WORK FOR A SOCCER TEAM OF HOSPITAL WORKERS}

With a view to promoting workers' mental health, minimizing professional stress and fatigue, we investigate the meaning of work, leisure and their implications for 24 male workers at a São Paulo hospital school, who are part of a soccer team and attend the recreation association of this unit. We chose to realize Research-Action from a humanist, qualitative approach, analyzing discourse according to categories, to be of help in elaborating the educational project. Data were collected through interviews and participant observation, using photography as a support instrument. Most participants are married, have children, receive an average salary of $R \$ 650.00$ and work near the unit, which favors contact for games. In their opinion, work guarantees personal and family survival, while leisure means fun, relaxing, integration and valorizing family and friends. They emphasize the importance of challenge in soccer as a means of promoting health, rescuing self-esteem, happiness, freedom, creativity, spontaneity, resulting in better preparation for personal and professional life.

DESCRIPTORS: health promotion; work; leisure activities

\section{EL OCIO, LA VIDA MÁS ALLÁ DEL TRABAJ O PARA UN EQUIPO DE FUTBOL ENTRE TRABAJ ADORES DE HOSPITAL}

Buscando la promoción de la salud mental del trabajador, en detrimento del estrés y la fatiga en el cotidiano profesional, investigamos el significado del trabajo y ocio para ellos, averiguando sus implicaciones en el cotidiano. En la Investigacion Acción utilizamos el abordaje humanista, cualiquantitativo, analizando datos por categorización. Investigamos 24 hombres, trabajadores de un hospital-escuela de una ciudad del Estado de São Paulo (Brasil), lo cuales frecuentan una asociación recreativa de esa institución y participan de uno equipo de fútbol. Buscamos lo datos por medio de entrevistas y observación participante, utilizando formulario y foto. En el análisis por categorización, los participantes se revelaron en su mayoría casados, con hijos, recibiendo en promedio $R \$ 650,00$ (seiscientos cincuenta reales) U\$ 220 dolares. Trabajan en locales cercanos dentro del hospital, favoreciendo contactos entre ellos para los juegos. Dan significado esencial al trabajo, garantizando la supervivencia personal y familiar. Valorizan las amistades y el fútbol, destacando esa actividad como medio propulsor de la promoción de salud, rescate de la autoestima, alegría, libertad, creatividad, espontaneidad, preparándole mejor para la vida personal y profesional.

DESCRIPTORES: promoción de la salud; trabajo; actividades recreativas

\footnotetext{
${ }^{1}$ Versão condensada da Dissertação de Metsrado apresentada à Escola de Enfermagem de Ribeirão Preto, da Universidade de São Paulo; ${ }^{2}$ Aluna de pós-graduação do Programa de Pós-Graduação, nível mestrado, e-mail: rcamargo@keynet.com.br; ${ }^{3}$ Orientadora, Professor Livre Docente. Escola de Enfermagem de Ribeirão Preto, da Universidade de São Paulo, Centro Colaborador da OMS para o desenvolvimento da pesquisa em enfermagem
} 
INTRODUÇÃO

Nossos estudos sobre o lazer e a saúde mental dos trabalhadores do hospital propõem-se a examinar as implicações do desenvolvimento de atividades recreativas, tendo em vista suas relações com o trabalho. Com isso, trabalhamos um quadro teórico para subsidiar a análise da prática não-formal do esporte, especificamente o futebol, mantendo, assim, um vínculo estreito e estratégico na promoção da saúde e na melhoria da qualidade de vida.

Desse modo, acreditamos que as pessoas só se motivam quando percebem claramente a possibilidade de prazer naquilo que fazem. Particularmente, neste estudo, dirigimo-nos às questões da motivação ou desmotivação do trabalho profissional. Se a aproximação ao prazer não nos é suficientemente clara, surgem as manifestações de descontentamento e insatisfação. O pêndulo entre o prazer e o sofrimento se concretiza, por vez, no cotidiano do trabalho e do lazer. A busca pela realização profissional e pessoal, a necessidade de ajudar as pessoas e a luta pela subsistência, confrontam-se com a submissão ao controle e ao poder autoritário, com as dificuldades para o desenvolvimento profissional, com a monotonia e o desgaste pelo ritmo de trabalho, com a necessidade de descanso e de afetividade na convivência com a família, de participação em encontros culturais e sociais, de praticar esportes e manter os corpos saudáveis, bem como de aspirar à liberdade, ao sentir-se sufocado pelas limitações que pertencem ao dia-a-dia dos trabalhadores, sobretudo do hospital.

Não obstante, o mundo do trabalho está cada vez mais associado ao estresse e o mundo do lazer, aspirado pela maioria das pessoas, como fonte de prazer, de liberdade e de promoção da saúde $e^{(1-2)}$.

Por outro lado, o conceito positivo do trabalho é coerente com a dinâmica de nossa sociedade industrial, que se baseia na eficiência produtiva e concede a primazia ao racionalismo técnico-econômico, isto é, uma sociedade de produção, aberta à concorrência, animada pelo motor do sucesso e presa ao bem-estar material. A educação e a formação técnica giram em torno da profissão. O lazer é considerado como um tempo de repouso e de consumo e a aposentadoria como salário bem merecido de uma vida de trabalho ${ }^{(3)}$.

Muitas vezes, não é possível alcançar equilíbrio entre as exigências da organização do trabalho e as necessidades, tanto fisiológicas quanto psicológicas, do trabalhador. Desse conflito, emerge um sofrimento que pode ser mais ou menos elaborado e apresentar repercussões mais ou menos acentuadas sobre a saúde mental. No entanto, o grande enigma não é a doença mental e, sim, a normalidade, isto é, o que importa realmente é compreender as estratégias defensivas (individuais e/ou coletivas) adotadas pelos trabalhadores com a finalidade de evitar a doença e preservar, ainda que precariamente, seu equilíbrio psíquico. São poucos os profissionais que podem se organizar para o lazer, de acordo com seus desejos e suas necessidades. Todavia, alguns dentre eles conseguem usá-lo harmoniosamente, de maneira a contrabalançar os efeitos mais nocivos da despersonalização ${ }^{(4)}$.

Reportamos essas questões à promoção da saúde do trabalhador, em se apropriando de sua realidade. $E$ reconhecendo os impactos do lazer sobre sua saúde, procuramos, a partir dessa lógica, construir e potencializar novas posturas e instrumentos que venha propiciar melhoria da vida, isto é, na qualidade do viver desses profissionais.

\section{OBJETIVOS}

De acordo com as nossas inquietações centralizadas na saúde mental do trabalhador do hospital, diante dos aspectos estressantes do cotidiano profissional, nossa investigação procurou compreender o significado do lazer e do trabalho emitido por esses trabalhadores, tendo como ponto de partida o futebol, entendido como estratégia defensiva coletiva adotada por eles, subsidiando o desenvolvimento de proposta educativa para o lazer e o trabalho, visando o reconhecimento e a construção do entorno saudável, ou seja, da promoção da saúde mental.

\section{METODOLOGIA}

Optamos, nesta investigação, pela modalidade de Pesquisa Ação, tratando-se de estudo exploratório e descritivo, com utilização de técnicas quali-quantitativas subordinadas a uma abordagem fundamentada em uma visão humanista. A pesquisa envolveu interação efetiva do pesquisador com os pesquisados, na identificação dos problemas, procurando compreender os sujeitos investigados em seu cotidiano. A abordagem pedagógica 
utilizada foi uma adaptação da educação conscientizadora $^{(5)}$. Na primeira etapa realizamos o levantamento do universo temático: seleção dos temas geradores, organização do material da coleta de dados, seleção e codificação de palavras e frases registradas/ emitidas, síntese das palavras e frases selecionadas, possibilitando a ordem dos temas geradores. Com isso, trabalhamos uma proposta para o desenvolvimento das atividades educativas.

Esse recurso metodológico insere-se na abordagem quantitativa (quando se aproxima do aspecto consensual), e na qualitativa (que se empenha em mostrar a complexidade e as contradições de fenômenos singulares, a imprevisibilidade e a originalidade criadora das relações interpessoais e sociais). A partir do recorte de um fenômeno aparentemente simples, são valorizados, então, os aspectos qualitativos, expondo a complexidade da vida, evidenciando significados ignorados da vida social ${ }^{(6)}$.

Local de investigação - realizamos o presente estudo no campo de futebol de um Clube Recreativo de uma Associação de Funcionários de um Hospital Escola, de uma cidade do interior paulista. Essa associação atende 2400 integrantes. Além de defender os interesses dos servidores do hospital junto à Administração, proporciona, também, desenvolvimento de atividades de lazer, apoiando as iniciativas socioculturais de seus participantes.

Sujeitos da pesquisa - fez parte deste estudo o trabalhador do hospital em exercício ativo da profissão, filiado à Associação dos Funcionários, que integra as equipes de futebol participantes do campeonato de futebol de campo, "Integração 2001", no período previamente definido para a coleta de dados. A amostra foi composta de 24 associados: 13 auxiliares de serviço, 4 auxiliares de enfermagem, 2 oficiais de serviço de manutenção, 1 técnico de laboratório, 1 enfermeiro, 1 agente administrativo, 1 encanador e 1 oficial de administração.

Aspectos éticos - para a coleta dos dados, os sujeitos, ao aceitarem em participar da pesquisa, assinaram um termo de consentimento, livre e esclarecido, garantindo sigilo das respostas e liberdade para interromper a sua participação caso se sentissem constrangidos, conforme observância das leis no Comitê de Ética em Pesquisa com Seres Humanos, da Escola de Enfermagem de Ribeirão Preto da Universidade de São Paulo (EERP-USP), da qual tivemos aprovação.

Coleta dos dados - optamos pela observação direta e participante, possibilitando-nos descrição e análise efetiva dos componentes da situação estudada, do local e suas circunstâncias, do tempo e suas variações, das ações e suas significações, dos conflitos e da sintonia de relações interpessoais e das atitudes diante da realidade. Através do uso da fotografia buscamos uma identificação perceptiva elementar: os movimentos, os gestos, as posturas, os trajes, os costumes, as tradições e o cotidiano dos sujeitos em uma partida de futebol ${ }^{(7)}$.

Por vez, encontramos na entrevista individual, face a face, o instrumento adequado para atender aos pressupostos de nossos objetivos, considerando que 0 entrevistador deve ouvir ativamente e com atenção receptiva todas as informações prestadas, quaisquer que sejam elas, intervindo, pois, com discretas interrogações de conteúdo ou com sugestões que estimulem a expressão mais circunstanciada de questões que interessem à pesquisa. Deve, então, permanecer atento às comunicações verbais e de atitudes, sem julgar o entrevistado, aconselhá-lo ou discordar das suas interpretações, nem ferir questões íntimas ${ }^{(6-8)}$. Assim, elaboramos uma entrevista estruturada, com questões norteadoras.

Análise dos dados - utilizamos o tratamento estatístico para a caracterização dos sujeitos e na busca das regularidades presentes nos depoimentos. Esse, no entanto, foi subordinado à análise qualitativa, voltada à apreensão do significado expresso nas falas investigadas, as quais nos revelaram a visão de mundo, os anseios, dúvidas e alegrias dos sujeitos pesquisados. $\mathrm{Na}$ elaboração dos dados, trabalhamos com 0 estabelecimento de categorias das falas emitidas durante a entrevista, optando pela representação escrita, quadros e gráficos.

\section{ANÁLISE E DISCUSSÃO DOS RESULTADOS}

Este estudo se efetivou em 2 momentos.

\section{Primeiro momento}

- Caracterização do grupo - nossa população é eminentemente masculina. Concentra-se, predominantemente, na faixa etária de 31 a 40 anos (58\%), sendo a grande maioria casada ou amasiada, com família constituída, de 1 a 3 filhos. Quanto ao ganho salarial mensal desses trabalhadores concentrou-se, 
principalmente, $80 \%$, na faixa de $R \$ 301,00$ a $R \$ 1.000,00$. Os trabalhos complementares são exercidos por $54 \%$ desses trabalhadores. Entretanto, não são regulares, ou seja, constituem "um bico". O nível de escolaridade de $46 \%$ do grupo é o $2^{\circ}$ grau completo e $21 \%$ incompleto.

- Dados referentes ao trabalho e lazer - apreendemos, através da fala dos trabalhadores, que o trabalho significa sobrevivência e segurança, contrapondo-se ao medo do desemprego ou do semitrabalho. Percebemos, também, contraposição entre o trabalho assalariado na instituição pública, que respeita os direitos trabalhistas, e os trabalhos autônomos, cujos ganhos não são previsíveis, gerando ansiedade e insegurança para aqueles trabalhadores com qualificação limitada. Nessa situação, pouco importa para eles se fazem o que gostam no trabalho, mas, sim, a segurança na garantia de sua subsistência. O mundo contemporâneo é domesticado pela submissão ao trabalho e todas as atividades são feitas como labores pela sobrevivência $^{(9)}$.

Tabela 1 - Representação qualitativa, por categorização, das respostas dos trabalhadores de hospital da equipe de futebol pesquisada, referente às questões: você gosta de seu trabalho e fale um pouco dele

SIGNIFICADO

RESPOSTAS EMITIDAS

DO TRABALHO

CATEGORIAS

Relacionada à necessidade de sobrevivência e segurança

"Trabalho pela segurança e necessidade", "ali é um paraíso", "já sofri bastante aí fora", "antes trabalhava o dia todo no sol, ficava devendo, passando necessidade", "lá é bom, é seguro", "já fiquei desempregado, é muito difícil as coisas", "passei muita dificuldade quando trabalhava por conta", "meu trabalho é tudo, sem ele eu não teria lazer"

Relacionado ao "O pessoal é bom, faço amizades", "a convívio social convivência com os colegas é boa", "gosto do serviço que faço, da convivência com as pessoas", "a amizade é boa, tem muita", "a gente acaba pegando amizade", "gosto dos colegas que colaboram".

Relacionado à satisfação pessoal

"A gente se realiza é a minha casa, não pretendo sair, não tenho o que criticar", "por causa do desafio, gosto de fazer meu trabalho e ajudar as pessoas, de interpretar exames, fazer diagnóstico de laboratório", "me sinto bem ajudando as pessoas", "é importante ter ocupação, se sentir útil, ainda mais a gente que lida com o paciente".

Relacionado ao "Quando os pacientes saem melhor, pelo

reconhecimento reconhecimento, não ganho muito, mas me profissional

Relacionado ao sofrimento sinto gratificado", "gosto do trabalho, porque ele visa o bem do paciente, principalmente quando ele agradece, a gente se sente fortalecido".

"É um lugar sofrido, pensei que ajudaria o paciente", "não gosto do ambiente, vejo pessoas tristes, sofrendo".
São descritos dois componentes, no que diz respeito ao conteúdo significativo do trabalho: aquele relativo ao sujeito e o relativo ao objeto ${ }^{(4)}$. Observamos, nas falas, que o significado do trabalho é evidenciado, pela maioria, como um meio de preservação da vida, ou seja, de subsistência pessoal e da família, e para a satisfação de desejos materiais, "para comprar os sonhos". Com relação ao objeto de trabalho, de um modo geral, para os pesquisados, a satisfação pessoal, é de natureza sublimatória*, mecanismo defensivo que quando em condições facilitadoras, permitem aos trabalhadores terem suas tarefas socialmente valorizadas ${ }^{(10)}$. Ainda com relação ao trabalho, os convívios sociais permitem o estabelecimento de vínculos de amizade com o grupo de trabalho, valorizado pelos pesquisados, que associam à necessidade psíquica de aceitação, reconhecimento, atenção e afeto. Acreditamos, então, que a valorização do trabalho é determinada pelas relações interpessoais estabelecidas com os colegas e pela segurança proporcionada quanto à satisfação das necessidades materiais.

Os pesquisados mencionaram que aquilo que menos gostam no trabalho são as atividades: as tarefas repetitivas, como lixar paredes, escavar valetas, e fazer a roupa da sala de cirurgia; as horas extras e excessos de rotinas; os horários de plantões aos finais de semana e feriados, apesar de considerá-los necessários, entre outras. Os trabalhos repetitivos e os automatismos impedem as satisfações criativas, que a revolução industrial eliminou, tornando o trabalho monótono, pouca coerência, podendo haver em uma vida que oscila entre o trabalho não gratificante e o desemprego ${ }^{(4)}$.

Alguns dos trabalhadores acreditam que o trabalho influencia fortemente o núcleo familiar, assegurando esses laços e evitando problemas com as drogas e a violência em geral. Violência nas relações conjugais, alcoolismo e doenças têm relação com as dificuldades no trabalho e isso toca em todos os membros da família, atingidos indiretamente. No sentido inverso, o prazer no trabalho e os benefícios provenientes da relação de trabalho e promoção da saúde também têm repercussões favoráveis nas relações familiares e no desenvolvimento psíquico e afetivo dos filhos ${ }^{(4)}$.

\footnotetext{
* Conceito psicanalítico. Mecanismo competente de transformar pulsões inconscientes, primitivas, individuais, em atividades de utilidade e reconhecimento sociais
} 
As representações emitidas nas falas desses pesquisados, sobre o significado do lazer, assemelhamse ao conceito da literatura. Ou seja, o lazer é compreendido como ocupação à qual o indivíduo pode entregar-se de livre e espontânea vontade, seja para repousar, seja para divertir-se, recrear-se e entreter-se, ou ainda, para cultivar o convívio social com amigos e principalmente familiar, livrando-se das obrigações profissionais, familiares e/ou sociais. Segundo um dos entrevistados, o lazer é a hora que fica à vontade, dono do seu próprio eu, sem compromisso e responsabilidade, fazendo porque gosta. E ainda, promover a saúde, ter preparo físico e descanso mental e conviver com os amigos e familiares.

Fica evidenciada, também, a aproximação do significado do lazer como uma pausa no trabalho, a qual existe apenas para distrair a vida de só trabalho. E aí o trabalho sendo encarado como sofrimento, responsável pelo estresse, pelas pressões cotidianas, enquanto o lazer é válvula de escape, um tempo para esquecer o serviço e os problemas, um descanso do trabalho, um passatempo para se aliviar, desconectar do trabalho.

O lazer pressupõe o trabalho e é fruto da Revolução Industrial $^{(2)}$. O modo de produção capitalista compreende a fragmentação não só do trabalho, mas do tempo, ou seja, a sistematização de horários e a submissão do trabalhador ao tempo relógio em detrimento do biológico, coerção que se estende à forma de trabalhar, agora regulada pela competência técnica, pelos rígidos horários e pela eficiência, de maneira a aumentar a produtividade para aumentar os lucros o que não significa aumento de salário para o trabalhador. O trabalhador, portanto, foi treinado a produzir mais, através de novos métodos de trabalho e, principalmente, competindo com o relógio. A resposta biológica, isto é, as doenças do trabalho não demoram a se manifestar, paradoxalmente promovendo o surgimento de mecanismos de defesa, respostas às coações sofridas pelos trabalhadores ${ }^{(4)}$. $O$ lazer, nesse sentido, pode ser compreendido como conquista dos trabalhadores, ou mesmo como mecanismo de defesa, que responde à necessidade de se sentirem libertos de obrigações que não causam prazer, realizando atividades em que possam exercer o livre-arbítrio, e se reequilibrarem dos transtornos do trabalho.
Tabela 2 - Representação qualitativa, por categorização, das respostas dos trabalhadores de hospital da equipe de futebol pesquisada, referente à questão: o que é lazer para você?

\section{SIGNIFICADO DO \\ RESPOSTAS EMITIDAS LAZER}

CATEGORIAS

Relacionado à "É divertimento, distração, diversão, descanso, refrescar a cabeça", "traz refrigir prazer e liberdade e relaxamento", "é prazer, é tudo", "é descontração, liberdade, são muitas coisas", "é a hora que a gente fica a vontade, dono do seu próprio eu", "a gente faz porque gosta", "é um momento de prazer e relaxamento, mas precisa ter disposição e tempo", "descansa a cabeça".

Relacionado ao "Trabalho só deixa estressado, descanso após o para esquecer o serviço e os trabalho problemas pessoais", "sou muito ligado ao que faço, no trabalho, e faço muitas cobranças pessoais, é uma válvula de escape", "não ter pressão, fazer o que quer", "descanso do trabalho", "é esquecer do trabalho, se aliviar", "se não tivesse o lazer, não tem como viver".

Relacionado ao "É uma das partes que desenvolvimento complementa o ser humano", "é pessoal e social desenvolver o melhor", "faz parte da vida, assim como a família e as amizades do futebol".

Relacionado à "É promover a saúde, é preparo promoção da saúde físico, descanso mental, amizade, relacionamentos, passatempo, esquecer dos problemas", "é tirar as energias negativas, descarregar", "é se aliviar", "é $50 \%$ da vida", "a gente se sente outra pessoa", "é exercício, manter a saúde, alegria, ver os colegas", "faz bem para a saúde", "a gente volta outro, com mais ânimo, mais am ável".

A associação a grupos, como no futebol, com motivações comuns, onde são valorizados por suas habilidades e ao mesmo tempo recebem atenção calorosa e amiga, demonstra claramente o enfrentamento dessas coerções, mas não obrigatoriamente uma confrontação direta do problema do trabalho causador de sofrimento, pois são distanciadas de seu ambiente de trabalho. Entendemos, assim, que o conformismo em relação ao trabalho não significa conformismo quanto a uma possível renúncia de prazer e liberdade, ou seja, permanece a busca pelas ocupações felicitarias ${ }^{(11)}$. Valorizado pelo grupo, o lazer é compreendido, então, como essencial e parte integrante da vida, na busca de liberação e prazer. Os pressupostos de lazer - tempo e atitude ${ }^{(12)}$ - são expressos também pelos entrevistados. Ou seja, acreditam que não 
adianta apenas ter vontade de realizar uma atividade de lazer, é preciso disponibilidade de tempo, assim como o tempo livre não garante a prática de uma atividade de lazer, já que essa depende de atitude consciente e culturalmente predisposta ao lazer.

Para melhor apreensão dos significados apresentados por eles, procuramos categorizar seus lazeres, favorecendo a classificação por convergências, proximidades e identificações, e uma classificação das atividades de lazer desenvolvidas pelo grupo ${ }^{(13)}$. Notamos que um número reduzido de atividades é reconhecido como lazer pelos sujeitos. As atividades físicas, associativas e turísticas são as mais citadas, sendo que as artísticas são mencionadas apenas por um dos entrevistados; as atividades intelectuais e manuais não foram citadas.

Tabela 3 - Representação qualitativa, por categorização, das respostas dos trabalhadores de hospital da equipe de futebol pesquisada, referente à questão: quais as atividades que você considera lazer?

\begin{tabular}{|c|c|}
\hline $\begin{array}{l}\text { CLASSIFICAÇÃO DAS } \\
\text { ATIVIDADES DE LAZER }\end{array}$ & RESPOSTAS EMITIDAS \\
\hline Físicas & $\begin{array}{l}\text { "Futebol", "academia", "praticar } \\
\text { esporte", "corrida", "caminhada", } \\
\text { "sinuca", "natação", "vôlei". }\end{array}$ \\
\hline Associativas & $\begin{array}{l}\text { "Levar as crianças no parque", "ir } \\
\text { ao clube", "passear com a família, } \\
\text { comer pizza", "churrasco com os } \\
\text { amigos", "bate-papo", "jogar " } \\
\text { baralho", "reunião com os amigos", } \\
\text { "tomar cerveja com os amigos". }\end{array}$ \\
\hline Turísticas & $\begin{array}{l}\text { "Viajar com a família a passeio", } \\
\text { "reunião com os amigos, com a } \\
\text { família junto", "ir para o sítio } \\
\text { pescar", "viajar para a praia", } \\
\text { "passear". }\end{array}$ \\
\hline Artísticas & "Desenhar". \\
\hline $\begin{array}{l}\text { Relacionadas ao consumo } \\
\text { de lazer }\end{array}$ & "Assistir filmes na TV". \\
\hline
\end{tabular}

O futebol, o passeio com a família, o encontro com os amigos e as viagens são as atividades mais populares entre eles. As manifestações sobre o futebol foram apaixonadas. O futebol, além de ser popular, é parte integrante da paisagem de nossas cidades. É só observarmos a periferia da cidade e encontramos inúmeros campos de futebol improvisados. Ponto de encontro entre jovens e adultos, o futebol é uma estratégia, cada vez mais utilizada no resgate da formação e desenvolvimento de crianças marginalizadas socialmente. A maioria informa que aprendeu a jogar bola na infância, e não conseguem imaginar a vida sem praticar esse esporte. Para esses amantes do jogo, o enfrentamento de situações problemáticas no trabalho, como reorganizar a escala para ser liberado para o jogo, e na família, quando são questionados sobre sua dedicação quase que exclusiva ao futebol, não diminui o ímpeto e a vontade de jogar. Ficam indignados, quando cedem às pressões da família ou são impedidos pela escala de plantão, principalmente quando a partida vale pontos. De um modo geral, os investigados acreditam que, além de ser uma distração, o futebol favorece um melhor condicionamento físico e o convívio com os amigos. Percebem os benefícios para o corpo e para a mente, registrando que ficam mais dispostos, porque correm, transpiram e brincam, além de confraternizar com os colegas.

As equipes são formadas por trabalhadores que gostam de jogar e têm certa disponibilidade de tempo, já que a maioria trabalha respeitando escalas de revezamento de plantão. Os convites para participar dos campeonatos costumam envaidecer o convidado, já que representam a valorização de suas habilidades. No entanto, o jogador (trabalhador) sabe que vai precisar "suar a camisa para merecê-la", e representar a equipe é, para eles, encarar o "desafio". Essa palavra é repetida continuamente nas entrevistas e significa levar o jogo a sério. A atividade é cercada de brincadeira e espontaneidade, mas o gol é necessário, e é esse o principal desafio. Jogar por jogar não tem graça, saboreando da vitória ou amargando a derrota. Todos têm a consciência de que o sucesso do jogo depende do desempenho eficiente da equipe. Não gostam de jogo fácil. O adversário deve ser um time competitivo, pelo menos com o mesmo nível técnico. Não existe o treinamento prévio ou o preparo físico dos jogadores. Cada participante sabe qual a função que melhor desempenha, reconhecida pelo grupo, já que os que estão em melhores condições são escalados. A crítica é elaborada antes, durante e após cada partida de futebol. A autocrítica é rigorosa. O banco, ou ficar como jogador reserva, é visto com desconfiança, mas também entendido como outro desafio a ser vencido.

Notamos que a equipe mantém um forte sentimento de união, antes do início da partida, abraçados em círculo, rezam e emitem um grito de guerra, ritual que antecede invariavelmente todos os jogos do campeonato.

O início do jogo é marcado por uma comunicação fortemente motivadora entre eles, para o enfrentamento destemido da equipe adversária. A linguagem peculiar no campo de jogo contém frases que incentivam, e outras que repreendem os participantes. Os xingamentos, que aparentemente agridem tanto os adversários como os 
próprios companheiros da equipe, representam a necessidade de extravasar as tensões, segundo um dos pesquisados. Essa linguagem é legitimada pelo grupo.

Percebemos que, durante o jogo, o comportamento individual em relação ao grupo e ao objetivo do mesmo é, geralmente, aberto às críticas. As exigências físicas, as habilidades com a bola e o autocontrole são colocados à prova, na busca do gol, mas todos são conscientes que, para tanto, a integração da equipe às competências de seus jogadores, aliados ao forte espírito cooperativo e solidário, são essenciais. Essa possibilidade de vencer é sempre acompanhada de uma estratégia, ou tática de jogo.

As emoções são responsáveis em parte pelas agressões que ocorrem durante o jogo. Os participantes reconhecem aquelas que são desleais daquelas agressões legitimadas pela disputa propriamente dita. O jogador considerado desleal é criticado e isolado pelo grupo, sofre punição, como suspensão dos jogos, ou é desligado de maneira formal ou informal, quando não mais é convidado a compor a equipe.

O gol é o ápice do prazer para a equipe vencedora. É quando se abraçam, compartilhando o júbilo. No entanto, na derrota, as críticas são implacáveis, as jogadas são analisadas e as falhas apontadas. Após o término do jogo, os comentários informais que sucedem à partida, invariavelmente acontecem também à mesa do bar, onde o bate-papo é animado, e as jogadas são repetidamente discutidas e analisadas.

Os rituais observados no campo, com pessoas abraçadas, fortemente ligadas pelo espírito de equipe, cada um sabendo o que deve ser feito, com uma estratégia prédeterminada, tendo em vista um desafio claro, numa crítica constante e construtiva e atitudes de cooperação e solidariedade, provocam motivação raramente vista em nossos grupos de trabalho no hospital. Essa constatação nos remete à reflexão sobre o ambiente e a organização do trabalho.

A lógica do capitalismo diverge dos pressupostos do lazer, o que o torna por vezes subversivo ao sistema ${ }^{(14)}$. As exigências veladas de horas extras se contrapõem às necessidades de lazer, ou seja, de um tempo livre para dedicar-se à família e às atividades de livre escolha, na busca do prazer e da liberdade e, principalmente, momentos de interação, nos quais encontram a autoestima, acolhimento e afeto, valorização expressa e evidenciada pela maioria dos entrevistados. Hoje, os avanços tecnológicos e a informatização ameaçam o mundo do trabalhador, causando ansiedade e o medo do desemprego ${ }^{(2)}$. Encontramos, aí, a explicação para a segurança encontrada na empresa pública, que se contrapõe à privada e/ou ao serviço autônomo. A garantia do tempo livre e do salário ao final do mês é muito valorizada por esse trabalhador, que coloca o trabalho em primeiro lugar, pois garante a sobrevivência, e o lazer num segundo plano, mas de importância vital para a vida familiar e para a sua saúde pessoal.

Houve unanimidade nas respostas apresentadas nas entrevistas sobre os benefícios do lazer, especificamente do futebol, como uma atividade que distrai, diverte e relaxa. Os pesquisados percebem uma alteração positiva do humor, quando voltam do futebol. "Ficam animados e bem-humorados", segundo um dos entrevistados "mais amável, em casa e no trabalho". Percebem diferença no grupo de trabalho entre aqueles que jogam bola e os que não jogam. Alegam que "os primeiros são mais alegres e comunicativos, enquanto os outros são quietos, isolados e mais tristes".

Depreendemos, conforme já expresso, que existe significado relevante para as questões de estresse no ambiente hospitalar, e a conseqüente ênfase à importância da recomposição das forças perdidas, o que nos remete à fala de um dos sujeitos pesquisados, quando declara que "no dia-a-dia, no momento que está estressado, fica pensando no futebol, também na hora de dormir e no trabalho, a bola que defendeu, ou a que passou, e o que o time poderia ter feito", evidenciando-se, aí, um mecanismo de defesa ${ }^{(4-10)}$.

Nossos sujeitos também são conscientes da necessidade de criar um entorno saudável para eles e seus familiares ${ }^{(15)}$. A preocupação com a promoção da saúde é evidenciada pela maioria dos entrevistados, principalmente no que se refere à saúde mental. Percebemos nas falas dos entrevistados a importância da auto-estima e do bem-estar físico. Para um dos sujeitos, "a vida fica mais saudável, aprende-se a conviver com as pessoas socialmente, e com disciplina". Para outro, "quando ele se sente bem, passa isso para as outras pessoas, um clima de conforto, e acredita que tem um desempenho melhor no trabalho". Para a maioria dos pesquisados, as lembranças do jogo são revividas durante a semana. Pensam sobre as mesmas, o que poderiam 
ter feito para melhorar e não cometer mais aquele erro ou, por outro lado, ficam saboreando o gol que fizeram ou que ajudaram a fazer, ou ainda a bola que defenderam e evitou a derrota da equipe. Quando se encontram durante o turno de trabalho, o assunto também é futebol. Agendam os jogos, avisam os participantes, discutem sobre o futebol dos profissionais ou apenas brincam entre si. Percebemos, por tudo isso, que esses trabalhadores se alimentam mentalmente do lazer vivido aos finais de semana, durante o trabalho.

Segundo momento

Projeto educativo para o trabalho e o lazer

Posteriormente à realização da problematização coletiva, levantada pelos sujeitos da pesquisa, no presente estudo, em torno das dificuldades relacionadas às temáticas do trabalho e do lazer, foi proposta pelo grupo a elaboração de um projeto educativo, para compartilharmos essas reflexões com os demais trabalhadores da instituição investigada, ressaltando os aspectos significativos na construção do entorno saudável na promoção da saúde mental, com oficinas pedagógicas que explorem o conceito de trabalho, lazer, promoção da saúde, saúde mental do trabalhador, esporte, futebol, valorização pessoal e profissional, relacionamento interpessoal e familiar, buscando integrá-los ao seu cotidiano.

\section{CONCLUSÕES E CONSIDERAÇÕES FINAIS}

Concluímos que, para o trabalhador estudado, a submissão ao trabalho está relacionada, acima de tudo, à necessidade de segurança e de provimento de sua subsistência e de seus familiares. Essa visão condicionada pelas condições de existência e pelos valores ideológicos impostos pela sociedade capitalista levam a desconsiderar indicadores importantes como a realização pessoal. Todavia, essa lacuna no trabalho é compensada pelos desafios que o lazer proporciona. O conformismo aparente em relação às imposições do trabalho não impede a busca consciente ou inconsciente das ocupações felicitárias, que proporcionam a possibilidade do libertarse do tédio do cotidiano, que nasce das tarefas repetitivas, forçosas, e das fadigas físicas ou nervosas que contrariam os ritmos biológicos, abrindo o universo real ou imaginário do divertimento, de uma livre superação de si mesmo, do poder criador e da busca de integração afetiva com seus familiares, colegas e amigos. Esse grupo encontra, no futebol, os elementos para o entorno saudável na promoção da saúde, da auto-estima, do bem-estar físico e mental, entre outros, e nos ensina que o desafio, o trabalho de equipe, a crítica construtiva, a disciplina, a educação, a valorização do outro e a diversão podem caminhar juntos em nome do prazer, da liberdade e da felicidade.

Por fim, faz-se necessário esclarecer que este trabalho pretende instigar pesquisadores e trabalhadores da área da saúde a valorizar a importância da relação entre trabalho e lazer para a promoção da saúde e para a melhoria da qualidade de vida das pessoas. Nossas reflexões buscam identificar os elementos que contribuem para a saúde e fomentá-los à medida que são questionados e contextualizados na comunidade. A opção de estudar uma população masculina que vivencia o lazer nos trouxe dados que resgatam os valores do prazer e da liberdade, por vezes tão reprimidos, mais ainda nas mulheres sobrecarregadas de afazeres da dupla jornada. Acreditamos, depois de realizada esta pesquisa, que se faz necessária a busca de significado mais rico para o trabalho, integrado-o a uma estratégia de humanização, que não prescinde do lazer do trabalhador. Esse caminho foi sugerido pelo grupo estudado, que desencadeou na construção coletiva de uma proposta de um projeto educativo, pautado na educação conscientizadora e libertadora desse trabalhador, através da crítica e do comprometimento com os valores éticos na criação de um entorno saudável para a promoção da saúde. É preciso que a enfermagem, integrante desse rol de profissionais, passe a questionar e refletir sobre o foco da presente investigação, pois está envolvida nesse contexto, quando vivencia, com cumplicidade, na sua prática, as angústias e as ansiedades dos trabalhadores que lutam pela sobrevivência, submetendo-se a turnos desumanos de trabalho, e às suas próprias limitações para o exercício de uma vida saudável, em equilíbrio com a família e o lazer. Assim, não tivemos a intenção de esgotar o assunto. Todavia, ainda que em visão parcial e reduzida, esperamos poder contribuir de forma significativa para estudos na área do lazer e saúde mental do trabalhador, vislumbrando avanços na promoção da saúde como um todo. 


\section{REFERÊNCIAS BIBLIOGRÁFICAS}

1. Bueno SMV. Contribuição ao Estudo da Aplicação do Lazer no Ambiente Hospitalar. [dissertação]. Ribeirão Preto (SP): Escola de Enfermagem/USP; 1981.

2. Dumazedier J. Lazer e cultura popular. 3a ed. São Paulo (SP): Perspectiva; 2000.

3. Krippendorf J. Sociologia do Turismo. São Paulo (SP): Aleph; 2000.

4. Dejours C. A loucura do trabalho. 5a ed. São Paulo (SP): Cortez; 2000.

5. Bueno SMV. Educação Preventiva em Sexualidade, DSTAIDS e Drogas nas Escolas. [livre-docência]. Ribeirão Preto (SP): Escola de Enfermagem/USP; 2001.

6. Chizzotti AC. Pesquisa em ciências humanas e sociais. $5^{\text {a }}$ ed. São Paulo (SP): Cortez; 2001.

7. Bruhns HT. Temas sobre lazer. Campinas (SP): Autores Associados; 2000.

8. Minayo MCS. Pesquisa social. 19a ed. Petrópolis (RJ): Vozes; 2001.

9. Albornoz S. O que é trabalho. 6aㅡ ed. São Paulo (SP): Brasiliense; 2000.

10. Pitta A. Hospital, dor e morte como ofício. 4a ed. São Paulo (SP): Hucitec; 1999.

11. Marías J. A Felicidade Humana. São Paulo (SP): Livraria Duas Cidades; 1989.

12. Marcelino N C. Estudos do Lazer. $2^{\underline{a}}$ ed. Campinas (SP): Autores Associados; 2000.

13. Camargo L L. O que é Lazer. São Paulo (SP): Brasiliense; 1999.

14. De Masi D. A Economia do Ócio. Rio de Janeiro (RJ): Sextante; 2001.

15. Kickbusch I. Promoção da Saúde: uma perspectiva mundial. In: Organização Panamericana de Saúde. Promoção da Saúde: uma antologia. Washington (DC); 1996. p.15-24. 